Relations industrielles

Industrial Relations

\title{
How to Negociate the Labor Agreement - An Outline Summary of Tested Bargaining Practice, par Bruce Morse, Trends \\ Publishing, Co., Detroit 1963. 62 pages.
}

\section{Jean-Réal Cardin}

Volume 19, numéro 3, juillet 1964

URI : https://id.erudit.org/iderudit/1021285ar

DOI : https://doi.org/10.7202/1021285ar

Aller au sommaire du numéro

Éditeur(s)

Département des relations industrielles de l’Université Laval

ISSN

0034-379X (imprimé)

1703-8138 (numérique)

Découvrir la revue

Citer ce compte rendu

Cardin, J.-R. (1964). Compte rendu de [How to Negociate the Labor Agreement An Outline Summary of Tested Bargaining Practice, par Bruce Morse, Trends Publishing, Co., Detroit 1963. 62 pages.] Relations industrielles / Industrial Relations, 19(3), 407-407. https://doi.org/10.7202/1021285ar

Tous droits réservés (C Département des relations industrielles de l’Université Laval, 1964
Ce document est protégé par la loi sur le droit d'auteur. L'utilisation des services d'Érudit (y compris la reproduction) est assujettie à sa politique d'utilisation que vous pouvez consulter en ligne.

https://apropos.erudit.org/fr/usagers/politique-dutilisation/ 
d'une outre, et ainsi on pourroit discuter des six autres fonctions sous le titre général de prise de décision.

Lo partie suivante expose les éléments des disciplines fondomentales pour les administrateurs: économie de gestion, comptabilité de gestion, relations humaines et sciences du comportement et enfin méthodes quantitatives d'analyse

Dans une dernière portie, on trouve des applications des concepts administratifs et des techniques d'onalyse oux activités d'une entreprise. L'outeur distingue à cet effet les trois octivités fonctionnelles classiques, d̀ savoir: administration manufacturière, administration financière et administration en \& marketing $>$.

\& Essentials of Manogement est un volume qu'il faut lire et conserver à la portée de la main

\section{Bertrond Belzile}

\section{How to Negociate the Labor Agreement - An Outline Summary of Tested Bargaining Practice, par Bruce Morse, Trends Publish-} ing, Co., Detroit 1963. 62 pages.

Cette petite ploquette de soixante-deux pages n'est pas autre chose qu'un compendium sur la technique de la négociation collective. C'est en quelque sorte un guide simplifié de la pratique de la négociation, de ses recettes, utilisées par les directions d'entreprises oyant à négocier ovec les syndicats.

L'auteur ne discute rien au niveau des grandes politiques du <management $>$ et ne fait aucune place à la «philosophie $\gg$. L'idée de base de ce petit ouvrage est simplement de mettre entre les mains du négociateur patronal un sommaire des principoux faits et méthodes de nature ò lui indiquer, d'une façon détaillée et ordonnée, les principaux jalons à poser à ses démarches lorsqu'il se trouve d̀ faire face oux représentants du syndicat.

II lui indique où trouver les faits, ies données nécessaires à son action, comment les organiser et les utiliser de la foçon la plus efficace possible.

Ce n'est même pas un traité sur la convention collective, comme nous en connaissons plusieurs, où souvent l'étude des différentes composantes de la négociation et de la convention sont étudiées méthodiquement, et où on ajoute des séries de problèmes, de «cas $»$ devant être discutés par les étudionts.
Ici, rien de celà, mais en revanche des informations détaillées quant ò l'importance des principales clauses, à la cueillette des données, à leur calcul, à l'organisation et à la présentation des contre-propositions patronales, aux attitudes à développer ou à bannir chez le négociateur, aux aspects légaux et stratégiques à respecter.

Somme toute un vade mecum très utile à la fois pour le négocioteur professionnel à qui il peut servir d'élément de comparaison ovec les pratiques de sa propre organisation, et au responsable d'une entreprise dépourvue de personnel spécialisé aux prises ovec une négociation et manquant d'expérience et de conseil. A ce dernier surtout, ce petit précis peut se révéler d'une très grande utilité.

\section{Jean-Réal Cardin}

\section{Quelques aspects du Droit de la Province de} Québec, par Louis Baudoin et al. Ouvrage publié ovec le concours du CN.R.S., Publication du Centre français de Droit comparé, Editions Cujos, Paris, 1963, $279 \mathrm{pp}$

L'ouvrage est un recueil d'études portant sur différents aspects du droit tel qu'il existe de nos jours dans le Québec. Publié avec le concours du Centre national de la Recherche scientifique et préfacé par l'éminent juriste français Léon Julliot de la Morandière, ce recueil est destiné avant tout ò mettre le monde juridique français au courant des principoles lignes de force et des problèmes les plus caractéristiques du droit québécois contemporain

Il est l'oeurre de juristes et de praticiens conadiens du droit, à la tête desquels il faut mentionner $M$. le professeur Louis Boudoin, de la Faculté de Droit de I'Université McGill

Comme le professeur Baudoin le souligne dans son étude, la Province de Québec est un laborotoire merveilleux de droit comporé, étont située géographiquement et historiquement, aussi bien dans l'ordre culturel que juridique, aux confins de civilisations différentes mais en quelque sorte complémentaires, si on sait les envisoger dans l'optique d'un monde en constante progression vers une plus grande solidarité.

Notre héritoge fronçais, ovec so mentolité, ses institutions fondamentales comme la famille et la paroisse, son droit civil codifié en 1866 et so langue; l'apport non équivoque des institutions politiques, constitutionnelles et de droit public de l'élément 